\title{
Article
}

\section{Trolling in asynchronous computer- mediated communication: From user discussions to academic definitions}

\author{
Hardaker, Claire \\ Available at https://clok.uclan.ac.uk/4980/ \\ Hardaker, Claire (2010) Trolling in asynchronous computer-mediated \\ communication: From user discussions to academic definitions. Journal of \\ Politeness Research, 6 (2). pp. 215-242. ISSN 1612-5681
}

It is advisable to refer to the publisher's version if you intend to cite from the work. http://dx.doi.org/10.1515/JPLR.2010.011

For more information about UCLan's research in this area go to http://www.uclan.ac.uk/researchgroups/ and search for < name of research Group>.

For information about Research generally at UCLan please go to http://www.uclan.ac.uk/research/

All outputs in CLoK are protected by Intellectual Property Rights law, including Copyright law. Copyright, IPR and Moral Rights for the works on this site are retained by the individual authors and/or other copyright owners. Terms and conditions for use of this material are defined in the policies page.

\section{CLoK}

Central Lancashire online Knowledge www.clok.uclan.ac.uk

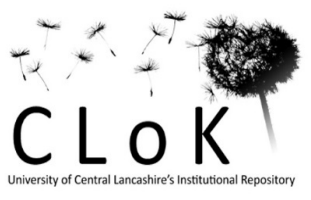




\section{Trolling in asynchronous computer-mediated communication: From user discussions to academic definitions}

CLAIRE HARDAKER

Abstract

Whilst computer-mediated communication (CMC) can benefit users by providing quick and easy communication between those separated by time and space, it can also provide varying degrees of anonymity that may encourage a sense of impunity and freedom from being held accountable for inappropriate online behaviour. As such, CMC is a fertile ground for studying impoliteness, whether it occurs in response to perceived threat (flaming), or as an end in its own right (trolling). Currently, first and secondorder definitions of terms such as im/politeness (Brown and Levinson 1987; Bousfield 2008; Culpeper 2008; Terkourafi 2008), in-civility (Lakoff 2005), rudeness (Beebe 1995, Kienpointner 1997, 2008), and etiquette (Coulmas 1992), are subject to much discussion and debate, yet the CMC phenomenon of trolling is not adequately captured by any of these terms. Following Bousfield (in press), Culpeper (2010) and others, this paper suggests that a definition of trolling should be informed first and foremost by user discussions. Taking examples from a 172-million-word, asynchronous CMC corpus, four interrelated conditions of aggression, deception, disruption, and success are discussed. Finally, a working definition of trolling is presented.

Keywords: Computer-mediated communication, conflict, impoliteness, troll, trolling

\section{Introduction}

Research into computer-mediated communication (CMC), the communication that occurs between humans via some form of computer, such as a desktop, mobile phone or similar (December 1997: 5; Ferris 1997; Herring 2003: 612) now spans over fifty years and covers areas as diverse as human-computer interaction (HCI), child-computer interac- 
tion (ChiCI) and computer-supported cooperative work (CSCW). However, whilst research has been conducted on the effects of, for instance, aggressive video games and their link with offline violence (e.g., Scott 1995; van Schie and Wiegman 1997; Dill and Dill 1998), little research currently investigates linguistic aggression online, possibly because CMC is perceived as frivolous, insignificant or marginal (Herring and Nix 1997: 1; Merchant 2001: 295; Cho et al. 2005). This paper seeks to begin to redress this balance.

Specifically, this paper argues that current terminology used in the field(s) of im/politeness ${ }^{1}$ does not comfortably describe the phenomenon of trolling ${ }^{2}$. Following Watts (2003: 9), this paper takes the view that "investigating first-order politeness is the only valid means of developing a social theory of politeness", but diverging from Watts and adopting approaches used by, among others, Culpeper (2010) and Bousfield (in press), the aim of this paper is to build a working definition of "trolling" from lay user discussions of this term. In short, the research question might be phrased as, "What academic definition of 'trolling' can be extracted from user discussions?"

Section 2 reviews recent and relevant impoliteness terminology and CMC research. Section 3 outlines the 172-million-word corpus of unmoderated, asynchronous $\mathrm{CMC}$ (ACMC) used in this research, and the methodology adopted. Section 4 analyzes user discussions of the terms "troll", "troller", "trolling" and so forth, and preliminary results suggest that trolling is manifestly made up of four interrelated characteristics: aggression, deception, disruption, and success. These are addressed in sections 4.1 to 4.4 . In section 5 , this paper begins to formulate a definition of trolling, and section 6 provides the conclusion.

\section{Im/politeness and computer-mediated communication}

This section covers several broad types and definitions of impoliteness, before outlining CMC and extant research on trolling. By necessity, these reviews are brief; far more could be, and indeed has been said on both impoliteness and $\mathrm{CMC}$, but given the limitations of this paper, only the most relevant aspects will be covered.

\subsection{Definitions}

As Watts (2003: 9) argues, “(im)politeness is a term that is struggled over at present, has been struggled over in the past and will, in all probability, continue to be struggled over in the future" and inevitably, growing interest in the field(s) of im/politeness has triggered a dramatic growth in terminology, such as "impoliteness", "rudeness", "face-attack", "conflict" 
and "incivility". In early research, particularly on politeness, "researchers focused on the structural properties of arguments or disputes, but gradually the focus shifted to more contextual strategies, and more recently, scholars are investigating how the self or selves is or are constituted through conflict and how ideology is constructed and reflected through conflict talk" (Kakavá 2001: 650). In other words, the emphasis has shifted from syntactic form with limited acknowledgement of contextual factors, to pragmatic function which attempts to account more fully for context and considers, but does not give undue prominence to, syntactic form. As such, researchers are latterly grappling with a potentially indefinite range of communicative behaviours (unintended lack of politeness, off-record insult), influenced by any number of contextual variables (power, distance, affect), rather than focussing purely on linguistic forms and structures (taboo words, commands, tagquestions) which, as per some earlier research in the field, were thought to be amenable to categorization as "more polite" or "less polite" (cf. Leech 1983).

One consequence of the evolving perspectives of im/politeness has been the growth and change of associated metalanguage, and the following subsections group together some of the major, academic impoliteness terms and their definitions found across a range of research. By necessity, this paper cannot account for every term, nor does it seek to enter the debate about which is more or less valid. Terminology certainly is "just one of many issues that face those interested in conducting research into and concerning 'impoliteness', 'rudeness', 'aggressive language', 'the causing of offence' or linguistic behaviour which may be otherwise recognized (if not termed) as socially-negative face-work will have to consider" (Bousfield in press). This work will instead argue more simply that none of the current terms is suitable for capturing the phenomenon of trolling. In section 5, these terms, their definitions, and their inability to comfortably describe and define trolling are returned to and discussed further. This paper finally argues that, though this will add yet another term to a field already burgeoning with many, it is needful to recognize "troll" and formulate for it a definition, in order to adequately understand and discuss this behaviour academically.

2.1.1. Ritual or mock impoliteness. Ritual, or mock impoliteness "is an offensive way of being friendly" (Leech 1983: 144), which, in AngloAmerican culture, can take the form of "sounding" or "playing the dozens", or in other words, using highly ritualized insults, usually rhyming and meant to be clearly untrue. In other words, whilst the form may contain features which a lay-person might consider to be inherently impolite, the function is actually to enhance and reinforce closeness, affect, 
group cohesion, and so forth between speaker/producer/writer (hereon $\mathrm{S}$ or, purely for alliterative convenience, she) and hearer/recipient/reader (hereon $\mathrm{H}$ or, again for alliterative convenience, he) (Haugh 2008). This is distinct from other forms of impoliteness which, under ordinary circumstances, are likely to encourage distance, disaffect, and division between S and H (Labov 1972).

2.1.2. Non-malicious impoliteness. Non-malicious impoliteness is an utterance performed without malice, but which $\mathrm{S}$ anticipates may cause offence anyway, such as when a tutor criticizes a students' work. Nonmalicious impoliteness is a by-product of S undertaking the task at hand, requirements of her role, or similar (Goffman 1967: 14; Culpeper et al. 2003: 1549; Culpeper 2005: 36-37). Due to the lack of malicious S-intent, it is arguable that this type of behaviour might not be classed as impoliteness at all. As above, however, it is not the point of this work to argue for the validity of the terms, but rather to show that they do not account for trolling.

2.1.3. Rudeness, faux pas, failed politeness. Culpeper (2005: 63) cites rudeness as the unintentional absence of appropriately polite behaviour, and Goffman (1967: 14) suggests that $S$ "may appear to have acted innocently; [her] offence seems to be unintended and unwitting ... In our society one calls such threats to face faux pas, gaffes, boners or bricks". Similarly, failed politeness (Beebe 1995: 166) covers instances where S intends to convey a polite attitude but misjudges the degree or type of politeness required, and thus causes offence (Culpeper 2005: 37). Cultural variation in the meanings of, for instance, interruption, silence, and directness can lead to an interpretation of impoliteness where none was intended. This type of impoliteness is H-interpretation-based, rather than S-intention-based (cf. failed impoliteness), and Bousfield (2008: 73) further distinguishes between failed politeness where $\mathrm{H}$ correctly recognizes that $\mathrm{S}$ did not intend to be impolite (but is still offended anyway), and instances where $\mathrm{H}$ incorrectly interprets malicious $\mathrm{S}$-intent.

2.1.4. Failed (malicious) impoliteness. Failed (malicious) impoliteness is S-intended impoliteness that is not correctly interpreted as such by $\mathrm{H}$. In other words, $\mathrm{H}$ either does not recognize impoliteness, or he misinterprets the utterance as, for instance, mock impoliteness, non-malicious impoliteness, or failed politeness (Bousfield 2008: 73).

2.1.5. Thwartedlfrustrated (malicious) impoliteness. Bousfield (2008: 72, note 6) outlines a further type of impoliteness which, for the sake of clarity, this paper terms thwartedlfrustrated impoliteness (Bousfield, per- 
sonal communication). In this case, although S's malicious intent is correctly reconstructed by $\mathrm{H}$, the impoliteness is frustrated, or thwarted, because $\mathrm{H}$ is simply not offended and either takes no action (i. e., frustrates the attempt), or counters with, for instance, sarcasm, contempt, amusement, or suchlike (i. e., thwarts the attempt). Bousfield (2008: 72, note 6) provides the example of a child trying, and failing, to insult a parent, however, impoliteness may still be thwarted/frustrated even when $\mathrm{S}$ is equal to, or more powerful than $\mathrm{H}$.

2.1.6. Genuine, malicious, or strategic impoliteness, or instrumental rudeness. These terms by Culpeper et al. (2003: 1546), Goffman (1967: 14), Lakoff (1989), Bandura (1973), and Beebe (1995: 159) respectively, refer to the kind of act that $\mathrm{S}$ carries out not only with the intention of causing $\mathrm{H}$ offence, but also of conveying that intent to $\mathrm{H}$. Bousfield (in press) offers a fuller definition of impoliteness as constituting:

[T] he issuing of intentionally gratuitous and conflictive face-threatening acts (FTAs) that are purposefully performed:

1) Unmitigated, in contexts where mitigation (where mitigation equates with politeness) is required and/or,

2) With deliberate aggression, that is, with the face threat exacerbated, 'boosted', or maximized in some way to heighten the face damage inflicted.

Furthermore, for impoliteness to be considered successful impoliteness, the intention of the speaker (or 'author') to 'offend' (threaten/ damage face) must be understood by those in a receiver role.

(Bousfield in press)

Within this definition of impoliteness, not only must $\mathrm{S}$ intend to be impolite, $\mathrm{H}$ must also correctly reconstruct her intent, though whether $\mathrm{H}$ then conveys back to $\mathrm{S}$ that he has recognized her intent is another matter entirely. To differentiate from thwarted/frustrated impoliteness, which is essentially identical except that $\mathrm{H}$ does not take offence, this paper refers to this as successful (malicious) impoliteness (Bousfield in press).

2.1.7. S-intention and H-interpretation. Throughout all of the above definitions, intention and interpretation are recurring issues. $\mathrm{H}$ (and analyst) must hypothesize from the evidence at hand, sometimes quite quickly, just what S actually intended (Culpeper et al. 2003: 1552; Mills 2003: 136). In impoliteness research these issues have only been more recently tackled. Previous frameworks tended to focus on S-intent (e. g., Brown 
and Levinson 1978, 1987; Lachenicht 1980) or on H-interpretation (e. g., Austin 1987, 1990), allowing the possibility that failed impoliteness on the one hand, or failed politeness on the other, might be analyzed as successful impoliteness. More recent research has begun to draw in both S and H (e. g., Culpeper 2005; Bousfield 2008,) but there is further work to be done, and this paper seeks to address this issue to some extent.

Mooney (2004: 900) suggests that rather than retrieving the actual intention itself, based on the available evidence, $\mathrm{H}$ will reconstruct S's intention(s) with variable levels of certainty, and arrive at one or more hypotheses of what they feel S may have intended:

Example (1) $[070807]^{3}$

1. A Either 1) You are a jerk. 2) You are stupid. 3) You are a troll. 4) All of the above. By your comments you are suggesting that the girl have somehow prevented this tragedy by the introduction of more electrolytes.

Example (2) [060915]

2. B She keeps challenging and asking questions like she is really interested in understanding our belief and logic then acts like the victim. Beginning to wonder if she is a troll or trying to get some type of ego trip, emotional gratification, or neurotransmitter "high" from debating/arguing.

Example (3) [060318]

\section{C I'm sorry, but I'm beginning to think you are a troll?}

As per the examples above, A posits two possible interpretations (an intent to troll, or to be a jerk - it seems unrealistic to suggest that one intends to be stupid), B offers two and $\mathrm{C}$ documents a change in her interpretation of another's intent. In each case, however, users may be interpreting an intent to troll where none is intended, and in other circumstances, users may fail to construct an intent to troll where it is intended. In other words, to reduce interaction to " $\mathrm{H}$ interprets $\mathrm{S}$ 's intent accurately" versus "H interprets S's intent inaccurately" is misleading. In ordinary interaction, we do not have the luxury of categorically knowing anything about S's real intent ${ }^{4}$. Instead, we are continually working from assumption, deduction, and premise, though we may at times have such confidence in our interpretations to feel that they are fully accurate.

The issue of intent/interpretation does not stop here. Both $\mathrm{S}$ and $\mathrm{H}$, consciously or otherwise, also assess their own and the other's utterances, and attempt to reconstruct the assessments of their own behaviour 
that the other has arrived at. For instance, $\mathrm{H}$ may assess S's utterance as follows: "Do I feel S's utterance has the potential to cause offence? Yes. Do I think they intended to be offensive? No. Am I offended? No." Meanwhile, S may reason thus: "I do not have impolite intentions. I do not think my utterance has the potential to cause offence. Do I think $\mathrm{H}$ will perceive that I intended to be impolite? No." (cf. Bousfield in press, Table 1). In this case, $\mathrm{S}$ may self-assess her behaviour as politic and judge that $\mathrm{H}$ sees it likewise, whilst $\mathrm{H}$ may view S's utterance as a faux pas. Other Hs may judge differently:

Example (4) [060929]

4. A That poster " $C$ " is a troll. Have you guys not figured that out yet? Read his post on [URL] and elsewhere.

5. B A I don't think $\mathbf{C}$ is a "troll".

Example (5) [030925]

6. D BTW [by the way], $\mathbf{E}$ is neither a troll nor is she baiting you any more than you are baiting her IMO [in my opinion].

Interestingly, this potential, or apparent, mismatch between S-intent and $\mathrm{H}$-interpretation is open to deliberate, complex exploitation by interactants. From H's perspective, as Culpeper et al. (2003: 1566-1567) discuss, $\mathrm{H}$ may interpret that $\mathrm{S}$ intends to be impolite, but, as a passive counter strategy, he may behave as though he has not interpreted it in an attempt to recast the impoliteness as failed. Alternatively, if he is offended, he may adopt an active counter strategy and respond as if he does recognize, but is unhurt by it, thereby attempting to reformulate the (perceived) attack as frustrated, thwarted, or mock impoliteness. If $\mathrm{S}$ cannot be sure that $\mathrm{H}$ correctly recovered her intent, then she may have to settle for what appears to be failed impoliteness.

From S's perspective, one way to attack and at the same time attempt to evade possible consequences is to use off-record malicious impoliteness. The assessment of the degree of on- or off-recordness may be negotiated and contested by the interactants over a number of turns (Aronson and Rundström 1989), but as on-record as S may make her utterance, this does not mean that her intent is, or ever becomes, retrievable. Rather, increased on-recordness means that fewer, and ultimately only one particular interpretation, can be reasonably attributed to her utterance. One reason that $\mathrm{S}$ may choose to be more off-record such that "there is more than one unambiguously attributable intention so that the actor cannot be held to have committed [her]self to one particular intent" (Brown and Levinson 1987: 69), is because incontrovertible, on- 
record attacks increase the risk that $\mathrm{H}$ may reciprocate with equal, or greater impoliteness (Culpeper 1996: 355; Andersson and Pearson 1999; Bousfield 2008: 220), potentially leading to a conflict spiral which could get entirely out of hand (Felson 1982: 245, Locher 2004). Another reason is that, by keeping her intent off-record, $\mathrm{S}$ makes it more difficult for $\mathrm{H}$ to hold her to account, since $\mathrm{H}$ may be unable to reconstruct her intent with enough confidence.

At the logical extreme, if $\mathrm{S}$ makes her attack off-record enough, $\mathrm{H}$ may not disambiguate the correct, or any, intent at all (Grimshaw 1990: 281). In the data, this very issue introduces a distinct bias towards predominantly discussing trolling according to $\mathrm{H}$-interpretation-based examples, since, for trolling to have a chance of succeeding, $\mathrm{S}$ must try to keep her trolling intent off-record, or deny accusations as they arise:

Example (6) [060318]

7. A If you are a troll ... I'm sure you'd never admit it. If there even is a *real* pony in all of this, I feel very sorry for it.

8. B I am not a troll ... I am only doing what my vet has advised me to do.

Example (7) [060514]

9. C If I say something that makes you nervous on account of your horsey experiences, that doesn't make me a troll.

Example (8) [090603]

10. D I am not a troll, you little jealous children.

Of course, B, C, and D may not be trollers at all, but given the inability of any individual to prove the "innocence" or "sincerity" of their intention(s), meeting the accusation with a denial is unlikely to resolve the issue. If a user's behaviour is clearly unacceptable, however, such as when S explicitly acknowledges a trolling intent, or if her posts are too unambiguously or repeatedly troll-like in nature, then it will increase the users' confidence in their interpretation, and taking action against the intent, rather that the content of her posts becomes a relatively incontrovertible affair:

Example (9) [030929]

11. A Killfiles, girls. Use your killfiles and send this troll to the muck pile.

In short, the net result of trollers attempting to keep their intent offrecord leads to few S-intent examples beyond straightforward denials, 
whilst $\mathrm{H}$-interpretation examples dominate. The bias towards H-interpretation is not insurmountable, but within the corpus, so far, there is only one instance where $\mathrm{S}$ openly declares an intent to troll:

Example (10) [050427]

12. A I love trolling on the horse news groups. It is just plain FUNNY. They have gotten used to my trolls. Any ideas on a good troll for the horse people?

There is no guarantee even here, however, that we have S's genuine intent on-record. For instance, this $\mathrm{S}$ may have entered the group, been heavily criticized for breaching norms, and then claimed to be trolling in order to save face, but whatever the case, the number of $\mathrm{S}$-intent examples does not begin parallel the sheer volume of $\mathrm{H}$-interpretation examples. With an increased corpus size it is reasonable to predict that there will be more examples, and whilst beyond the scope of this paper, it is being investigated for future research.

\subsection{Computer-mediated communication and trolling}

CMC has been variously praised and criticized by countless academics, lay users, and the media, for the profound impact it has had on almost every sphere of our lives, but for every benefit there is usually an opposing drawback. This paper only focuses on points most relevant to the analysis and discussion, but suffice it to say, this account is far from exhaustive. To summarise, $\mathrm{CMC}$ can allow those separated by time and space to communicate quickly and easily, but it cannot (fully) replicate $\mathrm{FtF}$ cues, thereby increasing the chances of miscommunication, and in turn, conflict (Zdenek 1999: 390; Herring 2003: 612). CMC allows people to create and maintain social and professional contacts in a way that would otherwise be nearly impossible, but it can also allow users to research the details of others, or even to contact them, for the purposes of crime, bullying, and so on. Further, CMC gives us access to unprecedented amounts of information on almost any topic, but that information can be dangerously wrong, and CMC can encourage us to feel a stronger sense of commonality with others than we might experience $\mathrm{FtF}$, potentially leading users to believe that they have more in common than they actually do (Thurlow et al. 2004: 54).

In short, the possibility of deception, whether intentional or accidental, or self- or other-imposed, is greatly increased in CMC (Spears and Lea 1992; Rheingold 1993; Preece 2000). This is because CMC can offer a very high degree of anonymity, and a great deal more control over a 
self-presentation than is available FtF, but this anonymity can also foster a sense of impunity, loss of self-awareness, and a likelihood of acting upon normally inhibited impulses, an effect known as deindividuation (Kiesler et al. 1984, Siegel et al. 1986). This, it is said, is manifested in behaviour such as flaming (Douglas and McGarty 2001: 399), and, this paper argues, in the closely related behaviour of trolling.

Whilst there has been academic interest in negatively marked online behaviours such as spamming (e. g., Stivale 1997; Barron 2006), cyberstalking (e.g., Bocij 2004) and cyberbullying (e.g., Strom and Strom 2005, Topçu et al. 2008), issues such as trolling and flaming have in general been left to popular literature (e. g., Shea 1994: Ch. 7) and the media (e. g., Black 2006; Cox 2006; Brandel 2007; Naraine 2007; Moulitsas 2008). There is surprisingly little academic research that bridges the gap between impoliteness on the one hand, and CMC on the other (see, however, Herring et al. 2002; Graham 2007, 2008; Shin 2008). Extant academic research employs the terms "troll", "trolling", and so forth in a variety of ways, drawing these definitions variously from the media, online ephemera such as The Troller's FAQ (1996), and personal intuition. As such, "trolling" has become a catch-all term for any number of negatively marked online behaviours.

For instance, Herring et al. (2002: 372) and Turner et al. (2005) describe trolling as the luring of others into useless, circular discussion, without necessarily involving argument, whilst Donath (1999: 45) and Utz (2005: 50) suggest that a troller may intentionally disseminate poor advice, thereby provoking others to correct them. Tepper (1997: 41) explains how trolling can delineate in-group/out-group membership: those who "bite" signal novice, out-group status, whilst in-group members will identify the troll, will not be baited by it, and may even mock those who are.

Perhaps more commonly recognized definitions, outlined by Baker (2001), Cox (2006), and Brandel (2007: 32), describe trolling as the posting of incendiary comments with the intent of provoking others into conflict. Naraine (2007: 146) also adds "ludicrous rants, inane threadjackings, personal insults, and abusive language" to the list. Meanwhile Donath (1999) and Dahlberg (2001) add a further aspect to this and suggest that trolling is a one-sided game of deception played on unwitting others who assume that the troller is sincere when, in fact, she is not: "The troll attempts to pass as a legitimate participant, sharing the group's common interests and concerns" (Donath 1999: 45). Then, "after developing their false identity and becoming accepted within a group, the troll sets about disrupting proceedings while trying to maintain his or her cover" (Dahlberg 2001). The main point, however, is that none of the research above takes its definitions from extended analysis of user- 
discussions of trolling. This work seeks to elaborate a more robust understanding of trolling, to argue for its validity as an object of research within the field(s) of im/politeness, and to provide a working definition in order to facilitate that research.

\section{Data and methodology}

The data for this paper is a corpus derived from a small subset of all posts available from the public domain, unmoderated Usenet newsgroup, rec.equestrian (RE). RE spans almost exactly nine years of interaction $(01 / 01 / 01-01 / 01 / 10)^{5}$ and is comprised of 186,470 posts.

WordSmith $^{\odot}$ (Scott 2009) was used to search the corpus for TROLL*6, and whilst this returned 2,284 hits, of these, an estimated $1 \%$ were false (e. g., trolley, trollop). This left over 2,000 hits that included inflections (troll, trolls, trolling, trolled), derivations (trolly, trollish, trolldom), neologisms (trollometer, trollbait, trollerita) and typographic errors (trollign, troll1). However, no search is currently able to retrieve off-record references to trolling (e.g., "it has a sub-bridge apartment"). Instances such as this were only captured if TROLL* happened to occur elsewhere in, for example, a more explicit reply by a user who had quoted a previous, off-record suggestion. Excluding false hits, all remaining examples were analyzed and classified according to what seemed to be the user's main point(s) or issue(s). This resulted in surprisingly few categories. Initially, only "deception", "aggression", and "disruption" clearly emerged as highly recurrent themes. On further analysis, however, "success" also emerged as a key feature. These characteristics, which are discussed in turn below, are taken to form the basis of the working definition given in this paper.

\section{User discussions of trolling}

Although in this analysis, four characteristics emerged, this is not to suggest that this list is exhaustive, or representative of all CMC environments.

\subsection{Deception}

$\mathrm{S}$-intent/H-interpretation is a problem for both $\mathrm{H}$ and analyst when attempting to distinguish a "sincere" online identity from an "insincere" trolling identity. As discussed in section 2.2 above, Donath (1999: 45) and Dahlberg (2001), appearing to view the phenomenon from S's perspective, describe how a troller will attempt to pass herself off as a legitimate member and after developing her false identity, she will set about 
disrupting the group whilst trying to remain under cover. In line with Donath (1999) and Dahlberg's (2001) description of trollers keeping their intent off-record, there are, unsurprisingly, very few examples of Ss going on-record to acknowledge their secret intent to troll the group beforehand (see example 10 above), though there are examples of users revealing an intent to troll after they have caused disruption or been "outed" as a troll. Instead, most examples are of users struggling to distinguish between "fictional" identities (whose professed intent is inconsistent with the user's real intent), and "real" identities (whose professed intent is felt to be sincere):

Example (11) [090920]

13. A While it's certainly possible this is a real email exchange, it would be a good idea to try to track down $B$ and verify that this is a real person - not a troll.

Example (12) [060313]

14. C Here's my opinion about the difference. Trolls are knowingly playing the group. They need some minimal savvy and intelligence to do it. Idiots, which I equate with netkooks, appear to seriously believe what they say.

Example (13) [071129]

15. D Well, if "she" follows suit like the troll "she" has been, there will be a change of name and identity and perhaps even gender, before the eventual reemergence.

Example (11) elaborates on the notion that the only way to be certain that an identity is "real", and not a deception, or in other words, a troller, is to know the owner of that identity offline. Example (12) suggests that this deception is wilfully and knowingly carried out, whilst (13) outlines the full potential extent of the role-playing that might take place. In this case, D describes a troller as someone who uses the anonymity that CMC provides as a means by which to enact an identity that is markedly inconsistent with that of his or her offline self, emphasizing the mutability of the identity (or indeed, identities) that someone may create online.

The problem for users, of course, is that an individual who appears to be a troller may simply be an inexperienced user who has misunderstood an aspect of $\mathrm{CMC}$, or who has acted upon expectations that others do not share, or a young or emotionally vulnerable individual: 
Example (14) [071116]

16. A But in truth it is at times hard to distinguish a mentally questionable, emotionally dysfunctional, lonely individual from a troll ... and many times the intent to troll might not be there but the impact is the same (because the individual cannot control his/her emotions.)

Example (15) [060317]

17. B If you think I'm a troll. I am not. I am a newbie. Learning how to use Usenet. (not a discussion board as I have been corrected)

Alternatively, the individual could be a troller who is playing upon these possibilities, since dealing with a user who appears to be acting, or trying to act, within the accepted norms for that activity type (Levinson 1979) will be more problematic. Confronted trollers may deny the accusations, plead ignorance or inexperience, brand those who block them as censorious or cowardly, or even accuse individuals who confront them of being trollers themselves (Herring 1999: 151; Herring et al. 2002: 377):

Example (16) [060516]

18. A Since everyone thinks I am a troll, I wont post here anymore. I didn't mean to come across the way I did, and this group doesn't mean anything to me anyway

Example (17) [070210]

19. B C is a troll.

20. C B is a very, very silly girl who is not quite sure what a troll is, but she knows how to repeat sneers from other happy group readers.

It is not always possible to confidently determine that someone is causing trouble intentionally and to label that person a troller. It is perhaps easier (for $\mathrm{H}$ and analyst) to identify behaviours that are troll-like, and then to asses that someone who continues these behaviours after being warned otherwise is probably a troller. If $\mathrm{H}$ cannot be certain enough that $\mathrm{S}$ intended to be maliciously impolite, then he may be forced to err on the side of caution in his response. Should he actively retaliate, or confront $\mathrm{S}$ on-record (line 22 below), then she too could utilize an apparent mismatch between $\mathrm{S}$-intent and $\mathrm{H}$-interpretation by denying malicious intent and framing her behaviour as non-malicious impoliteness, 
failed politeness, or mock impoliteness. If $\mathrm{S}$ is able to plausibly deny impolite intent (line 23), $\mathrm{H}$ may find himself cast in the role of prime aggressor, and being asked account for his behaviour:

Example (18) [031127]

21. A I never said I was having touble instilling simple stable manners in my horse (or as you so rudely put it ... my WP drudge) I am just PLAYING with this method out of boredom. And having a great time at it.

22. B Ah, you're trolling. That explains a lot.

23. A B, explain to me exactly how I am being a Troll. I am participating in a ng [newsgroup] about horses. Thats all. We are discussing a method of horse training that I like and you don't. I have stated from my original post that I was just playing with this method because I was bored. So how exactly does that make me a troll? Despite what everyone has said, I have not been dishonest with any of my posts, I have not been rude to any one, and I have not bashed their chosen method of training. All of which has been done back to me. If you think I am a troll I would like to know why.

This also problematizes the issue of the offensive-defensive strategies proposed Harris et al. (1986), since, in example (18), what B seems to view as defensive behaviour justifiably triggered by an off-record, or impending attack, A seems to view as offensive, unjustifiable, and unprovoked behaviour. In this case, each interactant possibly perceives themselves as defensively countering the other's offensive behaviour, and as such, the way each utterance is categorized would depend on the viewpoint adopted (Corsaro and Rizzo 1990).

A further type of troller described by Donath (1999: 45) and Utz (2005: 50), and named the pseudo-naïve troller by Donath (1999: 30), intentionally disseminates poor or false advice under the guise of being innocently unaware that the advice is wrong:

Example (19) [060922]

24. A Somehow you expect people to be diplomatic to you when you have been trolling us. [...] We only reply to your BS [bullshit] to keep others from thinking that you might be giving them useful advice. Each and every time you jump in with more of your dangerous advice you can rest assured that someone is going to call you on it. 
Example (20) [061017]

25. B Most newbies will not have the ability to recognize a troll post amid all the good advice posted, or the bad advice that is suggested and then refuted. Leaving bad (troll) advise unrefuted *will* mislead newbies who are diligently trying to educate themselves.

Example (21) [070130]

26. C D is a troll and posts dangerous advice to newbies ... trust me, I would filter him in a second if I didn't think his advice is dangerous and could hurt someone.

These examples highlight the bind that users find themselves in when they suspect that an ostensibly sincere user is giving out pseudo-naïve advice. A common method of dealing with trolling (discussed further below) involves refusing to engage with the troller, but the moral obligation of keeping inexperienced users and their animals from harm can outweigh the aggravation of "being trolled", or in other words, of responding to, or "feeding", a troller. This paper also suggests that pseudonaïve trolling should include not only the act of giving advice, but also of seeking advice in such a way as to provoke emotional responses:

Example (22) [060812]

27. A You're not a criminal, but we get a LOT of trolls here who pose impossibly naive scenarios in an attempt to start "flame wars."

Example (23) [060812]

28. B Since I can't possibly imagine that anyone could really be this naive or dumb in RL [real life], the best information I could offer would be to go do your silly trolling in another newsgroup.

Example (24) [031125]

29. C

I'm a new horse owner ...

30. $\mathrm{D}$

a troll posing as $\mathrm{C}$ wrote ... I'm a new horse owner

31. $\mathrm{E}$ who has the sign??

32. $\mathrm{F}$

Oh E, how COULD you? That just wasn't very nice! We should not make such assumptions that this poor, poor creature is not genuinely looking for help! And now we've missed our opportunity to help! My oh my! [snork] 
These examples describe, or allude to a pseudo-naïve question strategy that involves posing as a new user who is an inexperienced horse-owner with a highly naïve question or "cry for help", typically involving a highly emotive topic. However, this strategy has been used in RE so often that members even parody it:

Example (25) [051008]

33. A My horse is laying on the ground barely breathing. Until I can get medical/surgical on him and can then call the vet (not before next week), can you tell me: 1. what's wrong with him? and 2. do I even deserve a horse? Thanks in advance! Love, trollerita

The heightened sensitivity that RE users are likely to feel with regards to animal welfare and human safety presents would-be trollers with emotive openings to exploit, especially given the difficulty of trying to distinguish genuine "cries for help" from sophisticated trollers. This again places users in the bind of not wishing to engage with (or "feed") trollers, but of feeling morally obliged to offer assistance where horse or human welfare could be at stake:

Example (26) [050629]

34. A I've been watching this thread develop and, presuming you are not a troll (and I'll extend the benefit of the doubt) you really don't need to be thinking about this. You lack the fundamental knowledge and experience necessary to be caring for any more than your own animals.

Example (27) [060418]

35. B If you're not a troll, $x$-ray's aren't that expensive so call a vet with a brain in their head and get some taken.

As per both examples above, users occasionally highlight their inability to confidently judge S's intent by explicitly acknowledging their suspicion that the other user could be trolling, whilst also trying to offer the advice requested.

This leads on to the issue that since a troller is typically attempting to pose (however briefly) as a legitimate user, it can take members several posts to determine the troller's intent, and the data provided many examples of users offering interpretations of S-intent, conveying their level of confidence, and enquiring after other user's interpretations: 
Example (28) [060828]

36. A And then there's the (rapidly solidifying, at least for me) notion that B is your garden-variety troll desperately seeking something to fill an excess of spare time ...

Example (29) [060531]

37. C D says I'm being unfair to you, but you are surely strarting to smell like a troll.

Example (30) [060831]

38. E Y'know, F, I've been watching my troll-o-meter, and this one has been scoring high. I haven't *QUITE* decided that it has a sub-bridge apartment, but boy, it sure looks suspicious :)

In each example, users allude to their (growing) belief that S's real intent is to troll but that this intent is being concealed, and that it has taken several posts for these users to arrive at their interpretation with sufficient confidence. From this we can infer that a sophisticated troller may succeed in never being recognized as such at all, or that her intent may not be interpreted with enough confidence for users to feel justified in taking action against her.

\subsection{Aggression}

A second dimension that emerged from the data was using "trolling" to describe aggressive, malicious behaviour undertaken with the aim of annoying or goading others into retaliating:

Example (31) [051015]

39. A Your comments, all too often, come with only invective and insult and contain no content whatsoever. This latter is well within the definition of trolling and baiting.

Example (32) [060812]

40. B Trolling means posting idiotic messages to rile up a newsgroup or message board. 
Example (33) [060901]

41. C Look up the internet definition of Troll, and you'll see that people who flame and attack others online are the trolls.

Example (34) [070131]

42. D This poster is so argumentative, hostile and snotty and has such disrespect for women or anyone with a different opinion than he has, that reason can only conclude he is either a miserable human being, or a troll.

In the above examples, users outline a range of what they feel are trolling behaviours, which include more aggressive actions, such as insulting and attacking others, and negatively marked characteristics such as being "hostile", "snotty", and "idiotic". The aggressive dimension to trolling seems most consistent with both academic research and media coverage on the topic, which tends to focus on the incendiary comments that trollers post to provoke others into conflict (Baker 2001, Cox 2006; Brandel 2007: 32), such as the "ludicrous rants, inane threadjackings, personal insults, and abusive language" (Naraine 2007: 146).

\subsection{Disruption}

A third, less prevalent dimension found in the data was that of disruption; that is, causing aggravation without necessarily attacking a specific individual. Within RE, prototypically disruptive behaviour included meaningless, irrelevant, or repetitive posts aimed at attention-seeking or response-generating:

Example (35) [071114]

43. A The end of your world is coming near. Most of you will die in horrible pain, grilled alive by nuclear fire. The survivors will have to resort to cannibalism in order to survive, but sooner or later they'll also die. Everyone will die.

44. B Good grief, are the teenybopper trolls home for the holidays already ...

Example (36) [060106]

45. A No, like all trolls, your intent is to garner attention for your pathetic self. 
Example (37) [060119]

46. C At this point, most of D's responses are blatant trolling and attention seeking behavior rather than an interest in the discussion.

In example (35), trolling appears to be seen as a behaviour that is a general nuisance, though not necessarily personally aggressive or attacking towards a specific user or user-group. For clarity, this has been termed spam trolling, related to, but distinct from spam. Whilst both spam and spam trolling are typically unsolicited, impersonal, and irrelevant, spam is usually driven by commercial gain and, one presumes, is not intended to annoy recipients, whereas spam trolling is driven by the intent to provoke aggravated responses. Within the data, the distinction between disruption and aggression quite frequently blurred, since one prime way of causing disruption and provoking responses it to post aggressive comments, however examples (35)-(37) are perhaps closest to those cited in research by Herring et al. (2002: 372) and Turner et al. (2005), who describe trolling as the luring of others into useless, circular discussion which, though not necessarily aggressive in itself, may frustrate others with its unproductive nature (Tepper 1997: 41).

\subsection{Success}

One of the most interesting aspects of trolling that came to light was how trollers are appraised by users for their degree of success both in relation to the quality of the troll itself, and with regards to how others respond to the troller:

Example (38) [090723]

47. A A troll who/which gets no response, has failed.

Example (39) [060830]

48. B You're going to try to pull a loaded horse trailer with an S10? I think you're going to be minus an S10 in a hurry.

49. C He's a troll. You bit.

As in example (39), certain, usually sincere, responses to trolls, such as anger, shock, and curiosity, were considered "bites", or in other words, a demonstration by the respondent that he had unwittingly been deceived by the troller's professed pseudo-intent, and was unaware of her real intent. In order to curtail a troller's success, individuals frequently 
tried to explicitly manage the behaviours of other users (examples 40 , $41)$, or implicitly manage the behaviour of the troller via threats $(42,43)$ :

Example (40) [060515]

50. A

FOLKS THIS IS A TROLL STOP FEEDING IT

Example (41) [060807]

51. B All I asked was “where have you been!?”. I wasn't encouraging anything.

52. C Yes you were. Trolls should be ignored, not engaged in conversation.

Example (42) [031201]

53. D Haven't we used up all the troll food yet?

54. E Yeah, but I've got some D-Con left. And a night scope on my shotgun.

Example (43) [060622]

55. F Personally, I'm thinking the most appropriate treatment would be a 150 grain copper/lead bolus administered intracranially, but unfortunately, that's considered an "off-label" use for trolls, and there's so much paperwork involved in getting approval that it isn't worth the effort.

It was recurrently evident that not just any response was a success for trollers. Interestingly, some users adopted response strategies which aimed to fall outside of what the troller, and other users, might consider as "biting" or "being trolled":

Example (44) [051108]

56. A Fine or not, you went down in flames when you entered this newsgroup. Even the dullards on this bunch eat trolls breakfast and use their bones for toothpicks.

Example (45) [060515]

57. B Yes, of_course_it's a troll. So what? Troll-baiting can be fun.

58. C Precisely :) Especially when it reveals its weakness in its first post. 
Example (46) [060318]

59. D Umm ... E? Do you think F made up her hot_ail address all special for us, just for this post? (Google is your friend.) Do you think she really has a husband? Do you think she is really even a _she_? Wait. I get it!!! You're trolling the troll. Had me going for a minute there. $<\mathrm{g}>[$ grin $]$

In the above examples, users endeavour to jeopardize the troller's success by demonstrating their awareness of what they feel is her real intent, and by alluding to, or explicitly informing the troller not only of their ability to deal with her effectively, but that rather than being sport for the her amusement, as in examples (44) and (45), the users are capable of turning the tables and making sport of trollers. Most interesting, however, is example (46), which indicates the ability of users to entirely switch roles and take on a trolling identity in order to play a troller at her own game.

From this it seems clear that trolling is a more complex issue than simply launching unprovoked attacks on others; it is open to criticisms on its quality, effectiveness and success. Users are quick to criticize "bad", obvious, and unsuccessful trolls:

Example (47) [060504]

60. A

You might have to keep practising your trolling though. It's not very good.

Example (48) [060504]

61. B Worst troll I've seen in a LONG time. Must be a preteen.

Example (49) [050907]

62. C Why is anyone responding to this troll? In the history of the trolls we have had here, he is not entertaining.

63. D Yes, but he's a new troll. And he's really dumb, no matter what he says. Don't tell me you've never watched a cat tossing around a dead mouse and been amused ...

Example (50) [060112]

64. E You know not who you are dealing with ...

65. F Indeed I do- an exceptionally inept and entertaining troll.

In the above cases, the trollers were noted for their inability to troll well, their lack of entertainment value, and, conversely, for the entertainment 
they provide for being inept. In particular, the users in example (49) openly discuss the troller in the third person, at once employing the facesaving strategy of not engaging with the troller directly, and also the offensive face-attacking strategy of talking about the troller as though she is non-existent.

Equally, "good", sophisticated, successful trollers were appraised and critiqued by users:

Example (51) [060531]

66. A Ah ... now it makes sense. You *are* a troll! I suspected as much. I give it to ya, you were a bit (only a bit) more clever than most at the start but you couldn't help yourself could you ...

Example (52) [060317]

67. B Ok, I get it. Nice subtle troll. Fair play to you, you had me going there for a bit.

Example (53) [070114]

68. C It was a successful troll. I don't know why people do it. It must be a sort of perverted hobby, like graffiti or crapping in dressing rooms.

Example (54) [070213]

69. D One thing I can say for $E$ is that he's the most successful troll here, and everyone keeps contributing to his cause! Duh. STOP already.

Example (55) [060317]

70. F I think we are dealing with an exceptionally talented troll! She even has us talking about her in another thread. Without feeding the troll, we are feeding the troll.

This suggests that even though trolling is meant as an aggravation to users, it can become a two-sided game of point and counter-point where a troller seeks to deceive and attack, and knowledgeable users parry with critiques on the quality of the deception and the trolling, thereby addressing the troller's real intent, rather than her pseudo-intent.

\section{A working academic definition of trolling}

A primary issue with any im/politeness definition involves group norms of legitimate behaviour. In the case of trolling, one person's active debate 
is another person's troll, and as Donath (1999: 47) suggests, a group's character will determine not only whether a troller is harmful to the individual or the community, but whether a user is even deemed a troller at all. To return to the earlier argument put forward in this paper, currently, there does not appear to be an elaborated academic term that suitably captures trolling. Given that a troller actively intends to cause trouble, harm, or aggravation, terms such as non-malicious impoliteness and failed politeness by definition do not apply.

Interestingly, depending upon the context, group, and user(s) in question, trolling can come close to mock impoliteness. Internet communities whose users are inexperienced or vulnerable, or who invest personal trust, emotional commitment, and private information, may find trolling particularly hurtful, distressing, and inexplicable, and in such a context, trolling could not qualify as mock impoliteness at all. However, communities whose users are less vulnerable, or more experienced or emotionally detached, may in turn perceive trolling as closer to a ludic enactment of conflict, akin to a competition (albeit at times a fierce one). Even in this context, though, mock impoliteness does not fully account for trolling, since mock impoliteness aims to enhance, or reinforce closeness and affect, whereas being identified as a troller by users typically leads to the troller being ostracized.

Malicious impoliteness too does not provide an adequate definition, since trolling typically involves keeping one's real intent to cause trouble hidden behind a pseudo-intent to be sincere. As per Bousfield's definition, "for impoliteness to be considered successful impoliteness, the intention of the speaker (or 'author') to 'offend' (threaten/damage face) must be understood by those in a receiver role" (2008: 72), whereas in the case of trolling, to have a chance at success, the troller typically aims to conceal her malicious, trolling intent, and to instead deceive $\mathrm{H}$ into believing that she is a genuine group member whose intentions are sincere.

In short, this paper suggests the following, working definition of the term "troll": A troller is a CMC user who constructs the identity of sincerely wishing to be part of the group in question, including professing, or conveying pseudo-sincere intentions, but whose real intention(s) is/are to cause disruption and/or to trigger or exacerbate conflict for the purposes of their own amusement. Just like malicious impoliteness, trolling can (1) be frustrated if users correctly interpret an intent to troll, but are not provoked into responding (cf. example 35), (2) be thwarted, if users correctly interpret an intent to troll, but counter in such a way as to curtail or neutralize the success of the troller (cf. examples 44-46), (3) fail, if users do not correctly interpret an intent to troll and are not provoked by the troller, or, (4) succeed, if users are deceived into believ- 
ing the troller's pseudo-intention(s), and are provoked into responding sincerely (cf. example 39). Finally, users can mock troll (cf. example 25). That is, they may undertake what appears to be trolling with the aim of enhancing or increasing affect, or group cohesion.

\section{Conclusion}

It seems clear that part of the human condition is to find a degree of entertainment in conflict, whether in the form of high-risk sports, action films, violent computer games, or linguistic aggression in television programs (Culpeper 1996, 2005; Culpeper et al. 2003; Bousfield 2008). However, unlike these situations where the individual typically only watches or simulates conflict, online, with the protection of anonymity and distance, CMC users can exercise aggression against other real humans, with little risk of being identified or held accountable for their actions. Given the extraordinary prevalence of CMC in our daily lives, linguistic and $\mathrm{im} /$ politeness research into negatively marked online behaviours such as trolling is surprisingly scarce, but this paper hopes to highlight the importance of this area, and to add in some small way to the body of work that currently exists.

\section{Acknowledgements}

This paper was presented in an earlier form at the Linguistic Impoliteness and Rudeness II conference (Lancaster University, $30^{\text {th }} \mathrm{June}-2^{\text {nd }} \mathrm{July}$ 2009). My thanks go to the delegates there, and to the two anonymous reviewers, for their helpful feedback. I would also like to thank Derek Bousfield, Dawn Archer, and Preston Linguistics Circle (PLC) for their support throughout the development of this paper. Any remaining shortcomings are entirely my own.

\section{Bionote}

Claire Hardaker is a Lecturer in English Language and Linguistics in the School of Journalism, Media and Communication at the University of Central Lancashire (UK). Her academic interests predominantly revolve around linguistic aggression, $\mathrm{CMC}$ and cyberpsychology.

E-mail: chardaker@uclan.ac.uk

\section{Notes}

1. I use im/politeness and field( $(s)$ to reflect the debate regarding whether impoliteness and politeness should be seen as distinct entities. My view is that we cannot divorce them, but should view each as more than a mere absence, corruption, or mirror of its supposed opposite. 
2. For clarity, throughout, this work distinguishes between the 'troller' (the person), 'troll' (the message) and 'trolling' (the act).

3. All examples are as per the original with the following exceptions: (1) Bold emphasis is always mine. (2) For clarity and brevity, indenting punctuation $(>)$ and linebreaks have been removed. (3) Unclear/removed attributions have been clarified/ restored. (4) All personally identifying details are anonymized. (5) Glosses in italics and square brackets are mine, e. g., lol [laugh out loud].

4. Given the human mind's inner workings, we might argue that even S may not fully understand her own intentions.

5. My particular thanks go to Sebastian Hoffmann whose assistance was instrumental in obtaining the 2001-2004 data.

6. The asterisk $(*)$ wildcard denotes 'zero or more characters', so a search for CAT* will retrieve cat, cats, catch, cattle, etc.

\section{References}

Andersson, Lynne and Christine Pearson. 1999. Tit for tat? The spiraling effect of incivility in the workplace. Academv of Management Review 24. 452-471.

Aronson, Karin and Bengt Rundström. 1989. Cats, dogs, and sweets in the clinical negotiation of reality: On politeness and coherence in pediatric discourse. Language in Society 18. 483-504.

Austin, J. Paddy M. 1987. The dark side of politeness: A pragmatic analysis of noncooperative communication. Christchurch: University of Canterbury unpublished $\mathrm{PhD}$ thesis.

Austin, J. Paddy M. 1990. Politeness revisited: The dark side. In Allan Bell and Janet Holmes (eds.), New Zealand Ways of Speaking English, 277-293. Avon: Multilingual Matters.

Baker, Paul. 2001. Moral panic and alternative identity construction in Usenet. Journal of Computer-Mediated Communication 7(1). http://jcmc.indiana.edu/vol7/ issue1/baker.html (Accessed 09 March 2010)

Bandura, Albert.1973. Aggression: A social learning analysis. Englewood Cliffs, New Jersey: Prentice Hall.

Barron, Anne. 2006. Understanding spam: A macro-textual analysis. Journal of Pragmatics 38. 880-904.

Beebe, Leslie. M. 1995. Polite fictions: Instrumental rudeness as pragmatic competence. In James E. Alatis, Carolyn A. Straehle, Brent Gallenberger and Maggie Ronkin (eds.), Linguistics and the education of language teachers: Ethnolinguistic, psycholinguistics and sociolinguistic aspects (Georgetown University Round Table on Languages and Linguistics), 154-168. Washington DC: Georgetown University Press.

Black, Lisa. 2006. It's a troll's 'life' for some: Online games raise addiction concerns. Chicago Tribune. November. 1.

Bocij, Paul. 2004. Cyberstalking: Harassment in the internet age and how to protect your family. Westport: Praeger.

Bousfield, Derek 2008. Impoliteness in interaction. Philadelphia and Amsterdam: John Benjamins.

Bousfield, Derek. In press. Researching impoliteness and rudeness: Issues and definitions. In Miriam A. Locher and Sage Lambert Graham (eds.), Interpersonal Pragmatics (Vol. 6, Handbook of Pragmatics). Berlin and New York: Mouton de Gruyter. 
Brandel, Mary. 2007. Blog trolls and cyberstalkers: How to beat them. Computerworld. May 28. 32.

Brown, Penelope and Stephen C. Levinson. 1987 [1978]. Politeness: Some universals in language use. Cambridge: Cambridge University Press.

Cho, Hee-Kyung, Matthias Trier and Eunhee Kim. 2005. The use of instant messaging in working relationship development: A case study. Journal of Computer-Mediated Communication 10. http://jcmc.indiana.edu/vol10/issue4/cho.html. (Accessed 09 March 2010).

Corsaro, William A. and Thomas A. Rizzo. 1990. Disputes in the peer culture of American and Italian nursery-school children. In Allen D. Grimshaw (ed.), Conflict talk: Sociolinguistic investigations of arguments in conversations, 21-66. Cambridge: Cambridge University Press.

Coulmas, Florian. 1992. Linguistic etiquette in Japanese society. In Richard J.Watts, Sachiko Ide and Konrad Ehlich (eds.), Politeness in language: Studies in its history, theory and practice, $1^{\text {st }}$ edn., 283-323. Berlin and New York: Mouton de Gruyter.

Cox, Ana Marie. 2006. Making mischief on the web. Time Dec. http://www.time.com/ time/magazine/article/0,9171,1570701,00.html (Accessed 09 March 2010).

Culpeper, Jonathan. 1996. Towards an anatomy of impoliteness. Journal of Pragmatics 25: $349-367$.

Culpeper, Jonathan. 2005. Impoliteness and entertainment in the television quiz show: The Weakest Link. Journal of Politeness Research 1 (1). 35-72.

Culpeper, Jonathan. 2008. Reflections on impoliteness, relational work and power. In Derek Bousfield and Miriam A. Locher (eds.), Impoliteness in language: Studies on its interplay with power in theory and practice, 17-44. Berlin and New York: Mouton de Gruyter.

Culpeper, Jonathan. 2010. Impoliteness: Using language to cause offence. Cambridge: Cambridge University Press.

Culpeper, Jonathan, Derek Bousfield and Anne Wichmann. 2003. Impoliteness revisited: With special reference to dynamic and prosodic aspects. Journal of Pragmatics 35. 1545-1579.

Dahlberg, Lincoln. 2001. Computer-mediated communication and the public sphere: A critical analysis. Journal of Computer-Mediated Communication 7. http://jcmc. indiana.edu/vol7/issue1/dahlberg.html (Accessed 09 March 2010).

December, John. 1997. Notes on defining computer-mediated communication. CMC Magazine. January. http://www.december.com/cmc/mag/1997/jan/december.html (Accessed 09 March 2010).

Dill, Karen E. and Jody C. Dill. 1998. Video game violence: A review of the empirical literature. Aggression and Violent Behavior: A Review Journal 3. 407-428.

Donath, Judith S. 1999. Identity and deception in the virtual community. In Marc A. Smith and Peter Kollock (eds.), Communities in Cyberspace, 29-59. London: Routledge.

Douglas, Karen M. and Craig McGarty. 2001. Identifiability and self-presentation: Computer-mediated communication and intergroup interaction. British Journal of Social Psvchology 40. 399-416.

Felson, Richard B. 1982. Impression management and the escalation of aggression and violence. Social Psvchologv Ouarterly 45. 245-254.

Ferris, Pixy 1997. What is CMC? An overview of scholarly definitions. CMC Magazine. January. http://www.december.com/cmc/mag/1997/jan/ferris.html (Accessed 09 March 2010).

Goffman, Erving 1967. Interactional ritual: Essays on face-to-face behavior. Allen Lane: The Penguin Press.

Graham, Sage Lambert. 2007. Disagreeing to agree: Conflict, (im)politeness and identity in a computer-mediated community. Journal of Pragmatics $39.742-759$. 
Graham, Sage Lambert. 2008. A manual for (im)politeness?: The impact of the FAQ in electronic communities of practice. In Derek Bousfield and Miriam A. Locher (eds.), Impoliteness in language: Studies on its interplay with power in theory and practice, 324-352. Berlin and New York: Mouton de Gruyter.

Grimshaw, Allen D. (ed.) 1990. Conflict talk: Sociolinguistic investigations of arguments in conversations. Cambridge: Cambridge University Press.

Harris, Linda, Kenneth Gergen and John Lannaman. 1986. Aggression rituals. Communication Monographs 53. 252-265.

Haugh, Michael. 2008. Intention in pragmatics. Intercultural Pragmatics 5. 99-110.

Herring, Susan C. 1999. The rhetorical dynamics of gender harassment on-line. The Information Society 15. 151-167.

Herring, Susan. 2003. Computer-mediated discourse. In Deborah Schiffrin, Deborah Tannen and Heidi E. Hamilton (eds.), 612-634. The handbook of discourse analysis. Oxford: Blackwell.

Herring, Susan C. and Carole G. Nix. 1997. Is "serious chat" an oxymoron? Pedagogical vs. social uses of internet relay chat. Paper presented at the American Association of Applied Linguistics Annual Conference, Orlando, Florida. 11 March.

Herring, Susan, Kirk Job-Sluder, Rebecca Scheckler and Sasha Barab. 2002. Searching for safety online: Managing "trolling" in a feminist forum. The Information Societv $18.371-384$.

Kakavá, Christine. 2001. Discourse and conflict. In Deborah Schiffrin, Deborah Tannen and Heidi E. Hamilton (eds.), The handbook of discourse analysis, 650-670. Oxford: Blackwell.

Kienpointner, Manfred. 1997. Varieties of rudeness: Types and functions of impolite utterances. Functions of Language 4. 251-287.

Kienpointner, Manfred. 2008. Impoliteness and emotional arguments. Journal of Politeness Research 4 (2). 243-265.

Kiesler, Sara, Jane Siegel and Timothy W. McGuire. 1984. Social psychological aspects of computer-mediated communication. American Psvchologist 39. 1123-1134.

Labov, William. 1972. Language in the inner city: Studies in the Black English Vernacular. Oxford: Blackwell.

Lachenicht, Lance G. 1980. Aggravating language: A study of abusive and insulting language. International Journal of Human Communication 13. 607-688.

Lakoff, Robin T. 1989. The limits of politeness: Therapeutic and courtroom discourse. Multilingua 8. 101-129.

Lakoff, Robin T. 2005. Civility and its discontents: Or, getting in your face. In Robin T. Lakoff and Sachiko Ide (eds.), 23-43. Broadening the horizon of linguistic politeness. Amsterdam and Philadelphia: John Benjamins.

Leech, Geoffrey N. 1983. Principles of pragmatics. London: Longman.

Levinson, Stephen C. 1979. Activity types and language. Linguistics 17. 356-399.

Locher, Miriam A. 2004. Power and politeness in action: Disagreements in oral communication. Berlin and New York: Mouton de Gruyter.

Merchant, Guy. 2001. Teenagers in cyberspace: An investigation of language use and language change in chatrooms. Journal of Research in Reading 24. 293-306.

Mills, Sara. 2003. Gender and politeness. Cambridge: Cambridge University Press.

Mooney, Annabelle. 2004. Co-operation, violations and making sense. Journal of Pragmatics 33. 1601-1623.

Moulitsas, Markos. 2008. Ignore 'concern trolls'. The Hill. January. http://thehill.com/ markos-moulitsas/dems-ignore-concern-trolls-8-01-09.html (Accessed 06 June 2009).

Naraine, Ryan. 2007. The 10 biggest web annoyances. PC World, 141-148. December.

Preece, Jennifer. 2000. Online communities: Designing usability, supporting sociability. Chichester: John Wiley. 
Rheingold, Howard. 1993. The virtual community: Homesteading on the electronic frontier. Reading, MA: Addison-Wesley.

Scott, Derek. 1995. The effect of video games on feelings of aggression. The Journal of Psychology 129. 121-132.

Scott, Mike. 2009. WordSmith tools. Liverpool: Lexical Analysis Software.

Shea, Virginia. 1994. Netiquette. San Francisco, CA: Albion Books.

Shin, Jiwon. 2008. Morality and internet behavior: A study of the internet troll and its relation with morality on the internet. In Karen McFerrin, Roberta Weber, Roger Carlsen and Dee Anna Willis (eds.), Proceedings of Society for Information Technology and Teacher Education International Conference 2008. Chesapeake, VA: AACE. 2834-2840.

Siegel, Jane, Vitaly J. Dubrovsky, Sara Kiesler and Timothy W. McGuire. 1986. Group processes in computer-mediated communication. Organizational Behaviour and Human Decision Processes 37. 157-1587.

Spears, Russell and Martin Lea. 1992. Social influence and the influence of the 'social' in computer-mediated communication. In Martin Lea (ed.), Contexts of computermediated communication, 30-65. New York: Harvester Wheatsheaf.

Stivale, Charles J. 1997. Spam: Heteroglossia and harassment in cyberspace. In David Porter (ed.), Internet culture, 133-144. New York: Hampton Press.

Strom, Paris S. and Robert D. Strom. 2005. When teens turn cyberbullies. The Education Digest, 35-41. December.

Tepper, Michele. 1997. Usenet communities and the cultural politics of information. In David Porter (ed.), Internet culture, 39-54. New York: Routledge.

Terkourafi, Marina. 2008. Towards a unified theory of politeness, impoliteness, and rudeness. In Derek Bousfield and Miriam A. Locher (eds.), Impoliteness in language: Studies on its interplay with power in theory and practice, 45-74. Berlin and New York: Mouton de Gruyter.

The Troller's FAQ. 1996. http://www.altairiv.demon.co.uk/afaq/posts/trollfaq.html (Accessed 10 January 2001).

Thurlow, Crispin, Laura Lengel and Alice Tomic. 2004. Computer mediated communication: Social interaction and the internet. London: Sage.

Topçu, Çigdem, Özgür Erdur-Baker and Yesim Çapa-Aydin. 2008. Examination of cyberbullying experiences among Turkish students from different school types. CyberPsychology and Behavior 11.

Turner, Tammara Combs, Marc A. Smith, Danyel Fisher and Howard T. Welser. 2005. Picturing Usenet: Mapping computer-mediated collective action. Journal of Computer-Mediated Communication 10. http://jcmc.indiana.edu/vol10/issue4/turner.html (Accessed 10 March 2010).

Utz, Sonja. 2005. Types of deception and underlying motivation: What people think. Social Science Computer Review 23. 49-56.

van Schie, Emil G. M. and Oene Wiegman. 1997. Children and video games: Leisure activities, aggression, social integration, and school performance. Journal of Applied Social Psvchology 27. 1175-1194.

Watts, Richard J. 2003. Politeness. Cambridge: Cambridge University Press.

Zdenek, Sean. 1999. Rising up from the MUD: Inscribing gender in software design. Discourse and Society 10. 379-409. 